\title{
Equnhtorian
}

\section{Praça 13 de maio: do cine Eldorado aos dias atuais}

\author{
José Muniz Falcão Neto \\ Mestrando em Antropologia \\ Universidade Federal da Paraíba \\ muniz-cobain@hotmail.com
}

\section{RESUMO}

Este artigo tenta mostrar práticas de sociabilidade e lazer construídas nos tempos do cinema aos dias atuais na Praça 13 de Maio localizada na cidade de Mamanguape/PB. Partindo das observações diretas, de fotografias antigas, relatos orais e filmagens, percebeu-se como estas práticas apresentam importância dentro do nível social da cidade. Para tal, a vivência in loco foi fundamental para se ter uma compreensão dos processos constitutivos da praça. Portanto, o objetivo que aqui se apresenta é mostrar algumas experiências etnográficas tidas durante o tempo de vivência na praça, analisando os grupos, indivíduos, as formas de sociabilidade geradas nos tempos do cinema (Cine Teatro Eldorado) e os novos cantos e formas de lazer que se apresentam como atos de resistência. Palavras-chave: Antropologia Urbana; Cinema; Sociabilidades; Lazer; Resistência.

\section{Introdução}

Com o desenvolvimento da tecnologia e as mudanças sociais vão surgindo diversas formas de comunicação alterando as interações humanas, a pintura, a fotografia e logo após o cinema, a arte que com o passar do tempo vai mudando de expressão e se firmando sobre novos aparelhos e expressões estéticas e técnicas. No avanço da modernidade o cinema se firma como a sétima arte e vai mudando as relações e interações sociais por onde passa, em alguns lugares o novo é permitido ser conhecido graças às imagens do cinema e as pessoas vão fazendo parte do circuito promovido por este fenômeno da modernidade.

O filme, como espetáculo de massa, só pôde se generalizar depois de um período de aculturação, de transição, quando a compreensão uniforme das imagens se tornou uma prioridade e o cinema deixou de ser atividade marginal. Esta tran- 
sição aconteceu, nos Estados Unidos, no período dos chamados nickelodeons, que sucede o período dos vaudeviles. Assim, de 1906 a 1915 os filmes passam a ser exibidos como atrações exclusivas devido ao seu enorme sucesso, em grandes armazéns que eram transformados em cinemas do dia para a noite, impulsionados pela altíssima lucratividade do empreendimento (COSTA, 2005, p. 59).

Sendo assim, pensando nas transformações sociais causadas por este fenômeno, teve-se como ideia tentar perceber os modos de sociabilidade construídos pelo fenômeno cinematográfico. Apoiando-se já de uma pesquisa desenvolvida, Fotografias e memórias do cinema no vale do Mamanguape-PB, ficaram nítidos alguns locais que foram transformados com a introdução do cinema, locais estes que até os dias atuais são frequentados por pessoas da cidade, onde se encontram e promovem um circuito de sociabilidade.

Perante a pesquisa Fotografias e memórias do cinema no vale do Mamanguape $-P B^{1}$, que foi projeto de TCC de graduação, fez-se um recorte de alguns processos observados com a introdução do cinema na cidade de Mamanguape (Cine Teatro Eldorado), que permitiu perceber modos de sociabilidade geradas por este cinema na Praça 13 de Maio, que nos tempos de seu funcionamento na década de 60, 70 e 80 se localizava em frente a esta praça.

Neste sentido, esta pesquisa tenta mostrar numa perspectiva comparativa e processual, os modos de sociabilidade desenvolvidos na Praça 13 de Maio, localizada na cidade de Mamanguape-PB, frisando a época do cinema até os dias atuais. No entanto, o intuito aqui presente é de tentar entender os processos de sociabilidade gerados nesta praça nos anos do antigo cinema e nos dias atuais, isto é, não só ver os modos de sociabilidade nos tempos do cinema, mas, entender todo histórico de sociabilidade construído na Praça 13 de Maio em relação as mudanças no cenário político e social da cidade, pois com o passar do tempo, o cenário da praça foi mudando através do avanço econômico e social da cidade, em que nos dias atuais os frequentadores na visão da opinião pública ou "dominante" (ELIAS, 2000) são ditos como "desviantes” (OLIVEN, 2007), por fazerem uso de substâncias como a maconha.

Portanto, a finalidade deste trabalho é tentar compreender e mostrar que a Praça 13 de Maio sempre teve uma frequência de pessoas promovendo diversas maneiras de sociabilidade em um só espaço, inicialmente, com maior plenitude, na época do Cine Teatro Eldorado, inaugurado no ano de 1965. 
Porém, se percebe uma grande diferença na opinião pública nas duas épocas sobre a praça, na qual fica nítida a forma que é pejorativamente marginalizada nos dias atuais. Desta forma, o real motivo deste artigo, é analisar alguns modos de sociabilidade praticados nesta praça que nos dias atuais são ditos como algo contrário e clandestino, levados à marginalidade e à repressão.

\section{Praça 13 de Maio: do Eldorado aos dias atuais}

Localizada em frente ao antigo cinema e considerada patrimônio histórico da cidade, a Praça 13 de Maio desde sua construção tem uma grande frequência dos moradores da cidade. Por alguns relatos de antigos moradores a 13 de Maio era o point da época quando o cinema se encontrava ativo, as pessoas que não iam ao cinema ficavam na praça a conversar entre amigos, fazer seus encontros e comer o cachorro quente do doceiro ${ }^{2}$. Aglomeravam-se ainda mais pessoas quando as sessões cinematográficas terminavam, pois, com o término dos filmes elas se dirigiam a praça para conversar. Segundo Sóricri:

O cinema redirecionou as práticas de sociabilidade da sociedade mamanguapense a partir do momento em que quebrou o cotidiano interiorano da cidade. A praia; distante 30 quilômetros da cidade, a bica do sertãozinho; que com sua piscina e seu mini zoológico era destino certo de lazer dos cidadãos, a praça da igreja Matriz, foram gradativamente trocados pela Praça 13 de Maio e pelo cinema aonde a população, principalmente os jovens iam se encontrar e se divertir (SILVA, 2011, p. 21).

Tendo como relatos um dos fotógrafos antigos da cidade, Naldo, e o Walfredo David Júnior, filho do antigo dono (Walfredo David) dos Cinemas na região do vale do Mamanguape ${ }^{3}$, que frequentaram o Cine Eldorado, respectivamente, eles afirmaram:

Ali era a praça [13 de Maio], ali era cheio de gente toda a noite, até a pouco tempo tinha aula a noite já, acabou a pouco tempo já, mas naquele tempo tinha aula a noite, era aquele movimento de estudante ali e carro de som na frente do cinema anunciando filme, show, tinha muito artista ali para fazer show e era sempre movimentada aquela praça, né? (Naldo fotógrafo, entrevista).

Ali na Praça 13 de maio era ponto de encontro, namorar, quando terminava o cinema o povo ia namorar na 13 de Maio, o clima da cidade era outro, perdeu muito as cidades que não valorizaram o cinema, perderam muito as cidades que não valorizaram a área de lazer, hoje as pessoas só visam o consumismo, o capitalismo, né? é ter o dinheiro no bolso, ai vai concentra tudo numa capital [...] (Júnior da Locadora, entrevista).

Nesse sentido, foi uma praça que sempre teve uma grande movimentação 
de pessoas das diversas camadas sociais da cidade. Ao constatar os moradores da cidade de Mamanguape-PB ficou perceptível que pessoas de localidades e níveis sociais distintos se encontravam no cinema e após as sessões estas iam a praça ${ }^{4}$.

Diante de sua história, a praça passou por algumas reformas, lhe deixaram mais clara, com novos modelos de bancos, piso e o corte de algumas árvores históricas até chegar na arquitetura atual.

Nos dias atuais, a 13 de Maio é um lugar considerado por alguns cidadãos mamanguapenses como uma praça histórica e uma das mais belas. No entanto, as opiniões sobre a praça se dividem, algumas pessoas da cidade a rotulam como frequentada por pessoas "desviantes" (OLIVEN, 2007; VELHO, 2003). Nesse sentido, a praça ganha uma classificação de ser mal frequentada, causando um esvaziamento comparada as outras praças da cidade.

Quero dizer que os grupos criam o desvio ao estabelecer regras cuja infração constitui desvio e ao aplicá-las particulares, marcando-as como outsiders. Sob tal ponto de vista, o desvio não é uma qualidade do ato que a pessoa faz, mas sim a consequência da aplicação por outrem de regras e sanções ao "transgressor". "O desviante é aquele a quem tal marca foi aplicada com sucesso, o comportamento desviante é o comportamento assim definido por pessoas concretas." (BECKER, 1966, p. 8-9) Em outros termos, certos grupos sociais realizam determinada "leitura" do sistema sociocultural. Fazem parte dele e, em função de sua própria situação, posição, experiências, interesses etc, estabelecem cuja infração cria o comportamento desviante (VELHO, 2003, p. 24).

Um detalhe importante a ser exposto é: quem são esses freqüentadores? A maioria dos sujeitos que a frequentam participam da cena alternativa da cidade, ou seja, atores que não compartilham da "opinião dominante" (ELIAS, 2000) da comunidade mamanguapense.

Segundo Elias na obra Estabelecidos e outsiders, a opinião pública dominante seria aquela configurada por moradores já estabelecidos num determinado território, um padrão formalizado entre aqueles que compactuam de valores comuns opondo-se a determinados comportamentos que saem de suas configurações formais e vigentes, que implicam em relações de poder entre os grupos.

Nessa pequena comunidade, deparava-se com o que parece ser uma constante universal em qualquer figuração de estabelecidos-outsiders: o grupo estabelecido atribuía a seus membros características humanas superiores; excluía todos os membros do outro grupo do contato social não profissional com seus próprios membros; e o tabu em torno desses contatos era mantido através de meios de controle social como a fofoca 
elogiosa [praise gossip], no caso dos que o observavam, e a ameaça de fofocas depreciativas [blame gossip] contra os suspeitos de transgressão (ELIAS, 2000, p. 14).

Sua maior movimentação se deu com a inserção do Cinema em frente a ela, para muitos moradores aquela praça era altamente frequentada pelas pessoas que iam ao Cinema. Ali era seu ponto de lazer, assim sendo, com essa interação de pessoas se construíram relações sociais que se estabeleceram, predominaram e influenciaram a visão dos moradores sobre a praça, assim como também, os "circuitos" construídos naquele espaço (MAGNANI, 1996).

Entretanto, as dinâmicas sociais estabelecidas na praça se modificam nos seus diferentes horários e contextos. A Praça 13 de Maio foi construída pela administração do prefeito José Fernandes, no dia 01 de Novembro de 1945. Décadas antes já se iniciava a modernização da cidade em 1922, "transita o primeiro automóvel na cidade de Mamanguape, adquirido pelo dono do Engenho Piabuçu, Cel. Pompeu Homem de Lira" (ANDRADE e VASCONCELOS, 2005, p. 54).

Nos tempos atuais observa-se que, na parte da manhã há um caráter mais comercial, em que os quiosques se encontram abertos, neles se vendem lanches, almoços e bebidas alcoólicas. Uns vendem especificamente bebidas, no qual sua propriedade é mais um bar, outros mais lanches, como se fossem pequenas lanchonetes. Além desses estabelecimentos, se encontram também mototaxistas, taxistas, relojoeiros e etc. Há uma grande presença de pessoas circulando na praça, ao se moverem para suas localidades, sejam para locais de trabalho ou um simples trajeto do cotidiano, faz de seu ambiente predominantemente comercial, um ponto de encontro, em que algumas pessoas param para descansar e conversar um pouco.

$\mathrm{Na}$ tarde, não se modificam tanto as características ditas anteriormente. Entretanto, com o baixar do sol e o término das aulas, a praça começa a ser frequentada por uma grande parcela de estudantes de escolas próximas a praça, sendo eles advindos principalmente do Instituto Moderno, da Escola Padre Geraldo e da Escola Luiz Aprígio. Começa uma maior aglomeração desses jovens ao entardecer, além deles há ainda a presença de outras pessoas advindas de diversas localidades, contextos e grupos sociais. Entretanto, o movimento diminui bastante a partir das $18 \mathrm{~h}$, pois, o comércio vai até aproximadamente, às $19 \mathrm{~h}$. Os mototaxistas e taxistas terminam seu horário de traba- 
lho e as maiorias dos quiosques fecham. É raro haver outras barracas abertas a não ser a barraca da Tia, que é uma das únicas a abrir o bar na parte da noite.

Com o anoitecer e a diminuição do comércio na praça e em seu entorno, ela vai se configurando com a presença de moradores da cidade que a frequentam particularmente na parte noturna. Neste horário, temos um cenário especial na praça. Mas qual o motivo do adjetivo especial? Um deles é uma constância de pessoas consideradas, pela opinião dominante, desviantes, maconheiros, vagabundos, traficantes e, até mesmo, arruaceiros. No entanto, quem são essas pessoas? Quais e porque dos estigmas criados? Como os sujeitos assimilam estes estigmas? Quais os significados de seus discursos em relação à praça, o porquê de frequentá-la apesar dos estereótipos, de onde vêm essas pessoas, o sentimento de estar nela e não em outras praças, quais grupos que a frequentam e a relação entre eles?

\section{Alguns relatos, observações e experiências}

Os relatos, as observações e as experiências vividas e sentidas na 13 de Maio foram essenciais para compreender as dinâmicas e as relações sociais que nela se constroem. Partindo da vivência in loco e do método de observação participante, me deparei com demasiadas situações, discursos e projeções dos indivíduos que nela se encontravam, permitindo-me ter uma melhor percepção social do contexto etnográfico da Praça 13 de Maio.

Com as observações, anotações no caderno de campo, registros fotográficos e videográficos, teve o início a pesquisa escrita ${ }^{5}$ e fílmica ${ }^{6}$. As interações em campo foram essenciais para a reflexão das dinâmicas que ocorreram nos tempos antigos e atuais do contexto etnográfico, o trabalho de campo junto as observações participante foram momentos para compreensão das relações sociais que emergiram na praça. A seguir, esboçarei uma série de relatos a partir das observações feitas durante o tempo de pesquisa que permitiram a construção deste trabalho antropológico.

Lo que saben y hacen informante e investigador en la situación de campo aparece mediatizado por su interacción, interacción pautada en tanto está estructurada socialmente y no como una mera improvisación azarosa. De ahí que el trabajo de campo no sea sólo un medio de obtención de información, sino el momento mismo de producción de datos y elaboración de conocimientos. 
Esta premisa que impregna cada técnica e instancia de la investigación empírica permite asignar al trabajo de campo y sus vicisitudes un nuevo lugar en el conocimiento: de eventualidades y anecdotarios pueden rescatarse las huellas del proceso cognitivo y las vías para su construcción (GUBER, 2005, p. 53).

Luciana é uma moradora da cidade e frequenta a praça. No dia 18 de Outubro de 2013, por volta da meia noite na praça, ocupada por jovens em sua grande maioria e pessoas mais velhas, participando de um evento intitulado Som na Praça, tive contato com estainterlocutora. Amiga minhaháalguns anos, falamos um pouco a respeito de nossas vidas, sobre alguns acontecidos e sobre sua visão da praça.

Em nossa interação ela me falou um pouco de sua impressão, dizendo que era uma "praça maravilhosa" e que desde os tempos do cinema ela sempre foi linda. Ao tocar na palavra cinema pergunto se a mesma tinha frequentado o local e ela (Luciana) me respondeu que: "Não, eu tinha 4 aninhos e minha mãe não deixava eu vim para o cinema". Falou que a praça lotava de gente quando tinha cinema e que "as pessoas vinham pra cá para namorar, é por isso que levou o nome de praça da gala”. Assim, perguntei se ela sempre foi "sujeira" como é vista hoje, ela me respondeu que sim. Pois disse que "para aquele tempo né, as pessoas se pegando na praça e tal". Falou, remetendo ao conservadorismo existente na época e aos valores morais mais conservadores, em que essa prática era vista com outros olhos.

No entanto, outras pessoas ${ }^{7}$ falaram que a nomeação de praça da gala foi quando a feira se estabeleceu nas proximidades da 13, em que haviam bancas de feirantes que de noite não abriam e a praça era escura, daí as pessoas iam para praça para namorar e até mesmo fazer sexo explícito.

Sendo assim, pelo relato ouvido percebe-se que, a praça tem sido estigmatizada desde a ativação do cinema, cuja inserção possibilitou a socialização e a movimentação na 13 de Maio. Desta forma, defrontamonos com uma mudança no cotidiano mamanguapense construído pelo movimento das pessoas que iam ao cinema, isto é, exclusivamente pelo advento da modernidade naquele contexto, o cinema Cine Eldorado.

No dia 23 de outubro de 2013 aproximadamente umas 16h, passei em frente da Praça 13 de Maio, quando chego à praça me defronto com um pessoal tirando uns instrumentos musicais de dentro de um carro, ao che- 
gar mais próximo, percebi que as pessoas que carregavam os instrumentos eram os colegas da banda Burning in the Horizon, hoje chamada de Ponto letal.

Ao entrar em contato com um dos integrantes, o guitarrista base, perguntei-lhe o que iria acontecer naquela tarde dentro do corredor da praça, ele me relatou que eles iriam tocar no colégio, no entanto, o evento foi cancelado e eles tiveram a ideia de ir à praça realizar a apresentação. Ao escutar seu relato imediatamente fui à minha casa para pegar uma câmera e poder naquele momento registrar algo que jamais havia acontecido na praça, uma banda tocar ao ar livre, numa tarde de semana, especificamente uma quarta-feira, sendo exclusivamente uma banda de rock.

Depois de ter feito algumas filmagens, conversei com alguns presentes e integrantes da banda. Eles relataram que o real motivo de terem vindo para a praça foi que a diretora de sua escola proibiu a realização da apresentação da banda dentro do colégio. O motivo da proibição, disseram alguns, foi de que alguém havia atirado pedras no colégio, assim, chamaram a polícia, quando a polícia chegou ao local, disseram que o ato de depredação ao colégio tinha sido feito pelo o pessoal que estava de preto, indicando a banda e os jovens roqueiros que estavam de preto.

Podemos notar uma configuração acontecida na praça, uma ação que mudou o aspecto geral da praça em suas tardes semanais. Aspecto este que diz respeito a sua situação pacata, de encontros casuais e, especificamente, comercial. Vale ressaltar a escolha da praça pela banda, tendo inúmeras praças, os integrantes preferiram a 13 de Maio.

\section{Som na praça}

No dia 07 de novembro de 2013, numa noite de quinta-feira, as pessoas se aglomeraram na 13 de Maio para participar do evento intitulado Som na Praça. Naquela noite quem se apresentou foi Danilo Wagner, Jordão e Carlos Albuquerque, todos esses frequentadores da praça. O "Som na Praça" é um evento que acontece todas as quintas-feiras, no entanto, na quinta da presente data teve algo diferente, isto é, diferente das outras "quintas", esta do dia 07 foi efetuada com o som plugado em uma caixa amplificada, pois todas as outras vinham sendo apenas voz e violão.

Conversei com alguns presentes, um deles Jefferson Aurélio, que me re- 
latou que essa praça era a melhor de Mamanguape, pois só ali se tinha aquela "vibe massa". Entretanto, um pouco antes de conversar com o interlocutor, a polícia esteve rondando o local. Antes disso, dias atrás, tive a oportunidade de presenciar e fazer parte de uma averiguação da PM na praça na qual eu e mais alguns amigos fomos revistados. Após a averiguação, perguntei o porquê da ação, um dos policiais me respondeu dizendo que ali (na praça) estava ocorrendo o uso de substâncias como maconha e crack, e que haviam denúncias sobre este caso. Depois da resposta, pergunto o porquê de agirem tão repressivamente naquela praça, o mesmo que deu a resposta anterior disse: "Você não acha que a polícia deve fazer a segurança da sociedade? Estamos fazendo apenas o nosso trabalho". Após a ação foram embora. Saliento esta passagem, pois no dia 07 tivemos mais uma vez a presença da $\mathrm{PM}^{9}$ rondando o local, dito pelos frequentadores como algo do cotidiano da noite da praça. Perguntando a Jefferson sobre o fato da PM estar sempre rondando o local ele me diz que é só uma forma de amedrontar as pessoas.

"Som na praça"- Evento que acontece nas quintas à noite reúne pessoas para curtir um som mais alternativo, diferente do que é divulgado pela mídia local. Sujeitos que constroem atividades artísticas na cidade apresentam-se na praça. Entretanto, nos dias atuais esse evento não acontece mais, mas, há ainda apresentações musicais de bandas a partir de outros vieses, que são os bares que dão oportunidades aos músicos locais de se apresentarem.

Relato sobre o evento:

Jefferson Aurélio: Com todo respeito a Quinta Universitária ${ }^{10}$, realizada em Rio Tinto, eu prefiro o "Som na Praça", a famosa praça 13 de Maio daqui de Mama... Uma coisa que brotou aqui em Mamanguape e hoje, anima as quintas do pessoal chegado a um bom som democrático e de qualidade... Lá, todos podem levar os seus violões e tocar para a moçada curtir, ouvir e tomar aquela velha "biritinha" \#DjêLeve... Cada um com seus gostos e particularmente, prefiro a calmaria do recinto da 13 , do que a agitação de $\mathrm{RT}^{11}$. Vamos colocar essa ideia pra frente meus amigos, e nunca deixar morrer a nossa única fonte de animação aqui em nossa cidade!!! (AURÉLIO, 2013, online).

No dia 10 de novembro de 2015, ao sair da feira livre de Mamanguape local onde trabalho vou, como sempre, neste horário da manhã (aproximadamente $11 \mathrm{~h}$ da manhã) à praça tomar um café, fumar um cigarro e passar um pouco de tempo observando a sua movimentação. Ao chegar lá, me deparo com alguns colegas que estão regularmente ali, seja no turno da manhã, tarde 
ou noite, são eles $\mathrm{C}, \mathrm{S}, \mathrm{G}, \mathrm{JS}^{12}$, todos aparecem no curta produzido ${ }^{13}$. Além destas pessoas, na praça havia um número grande de estudantes, todos sentados nos bancos da praça.

Ao passar o tempo de conversa, observamos duas pessoas sentadas de um lado da praça, um casal hippie. Querendo interagir com o casal, JS nos chama para conversarmos com ele, então, saímos eu, JS, S e G. Chegando lá, conversamos sobre tatuagens, os trabalhos artesanais deles e sobre os lugares na região de Mamanguape que possuem rios e açudes. $\mathrm{O}$ que quero tentar mostrar e perceber nesta nota é a interação entre estas pessoas num só espaço que é a Praça 13 de Maio, para muitos, coisas desse tipo só acontece ali, por isso, apesar de haver outras praças na cidade, o casal preferiu se instalar na 13 de Maio. Antes de irmos ao encontro do casal, falávamos de coisas que já haviam acontecido na praça, como policiais fardados bebendo nos barzinhos da praça ${ }^{14}$, dos baculejos, dos momentos engraçados e festas, que de alguma forma mostravam as particularidades da praça.

\section{Bar Mundo da Lua: promoção da sociabilidade e também de outro lazer}

O bar Mundo da Lua é um estabelecimento montado por Ale Fernandes. $\mathrm{O}$ intuito do bar era de promover novas possibilidades de músicas na 13 de Maio, segundo Ale Fernandes, sua maior intenção de colocar o Bar nesta praça era por sua familiarização, pois há bastante tempo já frequentava a praça, falou que queria montar o emprendimento para poder dar um pouco mais de vida à praça, com as músicas que tocaria no botequim e apresentações de bandas locais que movimentaria o local e o estabelecimento.

Como sempre foi frequentada por malucos da cidade, isto é, pessoas da cena alternativa, as pessoas que iam à praça sentiam a falta de um bar que tocasse a música da galera. Nesse sentido, o bar Mundo da Lua veio com a finalidade de dar aos frequentadores um som e um lazer alternativo já promovido pelos seus frequentadores, mas agora com o point da galera, o bar. Além das músicas alternativas e as bebidas oferecidas, os frequentadores também jogam xadrez e dama para passar o tempo e se divertir, o bar se tornou um novo point de encontro dos frequentadores da praça. Os sons predominantes neste bar chamam a atenção de um público singular da cidade, entretanto, não 
causam o esvaziamento da praça, pelo contrário, as pessoas que vão ao bar estão também na praça e monta-se um circuito de interação entre o bar e a praça, muitos que compram bebidas no estabelecimento preferem ficar na praça.

Um detalhe importante é que a maioria dos frequentadores desse bar, como também, da Praça 13 de Maio, são pessoas que já se conheciam, alguns desde a infância. Percebe-se o encontro de até três gerações, pessoas que frequentavam quando iam ao cinema, o Cine Teatro Eldorado, como é o caso de João Cassiano. Segundo João, o cinema lotava a praça e além do cinema, havia o cachorro-quente do Doceiro que "era o melhor do vale". Outro frequentador do cinema e que experimentou essa refeição foi Ricardo", "assisti muito filme aqui no Eldorado, e o cachorro quente do Doceiro? Não tinha Mc Donald's, Big Mac e essas porcarias aí não, ele fazia o cachorro quente com os restos de legumes da feira, agora, era o melhor cachorro quente que já comi na minha vida”. Temos também o relato de Naldo fotógrafo, sobre sua experiência com o cinema:

A ia, não só eu, aquela turma da minha idade na época tava ali, na general Vitorino. Aquela garotada da minha idade, 10 , porque eu só passei a ir para o cinema, só depois dos dez anos de idade, né? Sozinho eu não ia, só ia se fosse com uma pessoa, no caso. Mas naquela época a gente fazia qualquer coisa, vendia picolé na rua, pegava frete, para o sábado e no domingo, né? A feira era no sábado, no domingo, ai passou para o sábado, procurava o dinheiro da gente ali pegando frete, vendendo um picolé, um negócio, para ir ao cinema e comer um cachorro-quente que tinha aqui um tal de Doceiro, que foi famoso naquele tempo (risos), era, todo mundo fazia isso, é, tinha que tá lá. Pra tu ter uma ideia, o cinema aqui era tão concorrido pra assistir, que eu e esses menino lá, uns quatro a cinco assim da rua ali, a gente ia cedo, quando a bilheteria abria a gente comprava, ai ficava todo mundo numa fila só, numa fila só, que depois o cinema enchia e chegava aqueles casais e não tinha canto pra sentar não, ai a gente vendia o canto, "eu vendo o canto" [risos], eu dizia: "eu vendo", ai o outro "eu vendo o meu também", ai vendia pro casal, era assim, fazia isso. [...] Era de todo canto da cidade. E na sexta feira da paixão, ave maria, era gente demais, a fila dava até na maternidade. [...] Teve o tempo que começou aqueles faroeste, essas coisas, Tarzan, vije, quando botava um filme de Tarzan aqui, homi, tinha que tá lá de seis horas se não num pegava canto não [risos] (Naldo fotógrafo, entrevista).

Osdoisprimeirosinterlocutores frequentamapraça,JoãoCassianoeRicardo, enquanto o segundo, Naldo fotógrafo, só a frequentou nos tempos do cinema. Os relatosserviramcomoferramentasparaanáliseeregistro,podiainterpretarsituações econtextos históricos para compreenderos ditos enão ditos do campo de pesquisa:

[...] o relato oral se apresentava como técnica útil, para registrar o que ainda não 
se cristalizara em documentação escrita, o não conservado, o que desapareceria se não fosse anotado; servia, pois, para captar o não explícito, quem sabe mesmo o indizível (QUEIROZ, 1988, p. 15).

Os relatos foram de extrema importância para descrever as experiências passadas dos interlocutores e dos atuais frequentadores.

\section{A experiência da festa e vários grupos num só espaço}

No dia 14 de novembro de 2015, houve uma festa no bar que trouxe várias pessoas da cidade, como sempre vem acontecendo nos finais de semana. O que pudemos perceber foi a diversidade de pessoas ocupando os diferentes espaços da praça. Apesar de ter tido uma grande afluência de pessoas, notamos que os grupos formados ficaram em diferentes locais, como disse um dos presentes, chamado DC, "cada um no seu espaço e já era." Um detalhe importante dessas festas é que estam trazendo pessoas de outros locais, principalmente da Universidade Federal da Paraíba, do campus IV (Litoral Norte), e dando oportunidade às bandas e músicos locais para fazerem o som na praça, em destaque a banda D'gradê, Danilo Wagner e os Almaz, Samuel Avelar, Los Wagas e alguns Djs. Alguns deles são da universidade, como Breno, estudante do curso de graduação em Design.

Através desses relatos e experiências percebemos que a praça vem mudando constantemente, algo normal para um local situado em uma cidade em desenvolvimento econômico. Hoje ela está mais movimentada, seja na parte da manhã, tarde ou noite, isso graças à abertura dos bares ao redor, em especial, o Bar Mundo da Lua que é o mais frequentado pelos jovens da praça, funcionando com plenitude no turno da noite.

Outro bar foi aberto recentemente na praça após o fechamento do bar da Tia. Depois de alguns meses outro morador da cidade alugou o estabelecimento e o abriu especificamente na parte da noite, dando outra dinâmica à praça, pois neste tocam músicas variadas, desde forró a rock, aglutinando outro público na 13 de Maio. Concomitantemente, em frente à praça foi aberta uma escola de enfermagem, Escola de Enfermagem Rosa Mística, que influência a movimentação na praça e nos bares noturnos com seus estudantes.

O novo bar instalado foi aberto ainda este ano, enquanto a Escola de Enfermagem Rosa Mística foi aberta ano passado, antes se lo- 
calizava em frente à Praça do Rosário. Com esta nova inserção os bares e a praça tomam outra configuração pelos novos indivíduos que a frequentam, dinamizando ainda mais o local e promovendo maior interação por pessoas de diferentes características no turno da noite.

Algo a ser descrito e observado é os circuitos de turnos entre aqueles que especificamente circulavam mais na parte da noite que agora circulam na parte da manhã e tarde, fazendo uso da maconha em qualquer horário. Segundo JS: "é a resistência aqui na 13, é maconha e num tem isso não". JS é um dos que freqüentam em vários turnos a praça, essa sua frase é reflexo do uso constante de maconha na praça mesmo com a repressão da Polícia Militar. O relato foi feito quando estávamos na praça na parte da tarde, no momento portava uma câmera para fazer algumas filmagens e fotografias, na hora em que filmava o interlocutor se expressou dessa forma, de maneira a deixar claro que independente do horário e da repressão policial ele iria fazer o uso da maconha naquele local e naquele horário, reafirmando a resistência em relação às repressões policiais.

Em relação a este psicoativo, o uso dele se torna cada vez mais frequente independente de horário. Como frequentador da praça e pesquisador, parto do ponto de vista que nos tempos atuais a maconha na praça não é tão vista vulgarmente como antes. Os motivos são os pequenos passos que a justiça brasileira dá em relação aos usuários e os diversos usos deixando a população brasileira mais informada sobre a cannabis. Outro motivo seria que o uso frequente nos diferentes horários possivelmente acostumou as pessoas com o cheiro e a movimentação das pessoas que fazem o uso dela na praça.

Isto fez com que os indivíduos que não fazem uso dessa planta tivessem outro olhar sobre ela. Como sabemos e ouvimos relatos sobre a maconha, muitos se enganam quanto aos seus efeitos, e, ao verem que se faz o uso livremente e ainda se promovem sociabilidades na cidade e na praça. As pessoas veem que o uso não transforma os usuários, nem mesmo os induzem a fazer algo violento e transgressor, como divulgam os meios de comunicação da cidade, mas ao contrário, faz-se uso, e promovem-se sociabilidades, sejam em rodas de conversas após os becks, ou através de criações artísticas como pixo, grafite, cinema e música.

Contudo, relato esta percepção sobre o psicoativo a algumas pessoas que especificamente trabalham ao redor da Praça, especialmente nos bares, 
que estão diariamente em contato com estas dinâmicas e não a visão da cidade de modo geral e de outras pessoas que também tem estabelecimentos que se encontram entorno do contexto etnográfico, as quais são totalmente contrárias ao uso do psicoativo e aos usuários. Os estigmas e comentários depreciativos sobre o local e seus frequentadores continuam, seja pela população ou pelos meios de comunicação da cidade que diversas vezes anuncia algum tipo de denúncia contra os usuários na praça, como também, as diversas presenças da Polícia Militar nos baculejos habituais sobre os frequentadores, especialmente na parte da noite, reafirmam o caráter criminalizador dos discursos pejorativos sobre a 13 de Maio e seus frequentadores.

No percurso da pesquisa foram feitas várias filmagens para compor um curta metragem sobre as sociabilidades e vivências promovidas pela praça. Nestas imagens estão os principais atores que a frequentam. Algo de relevante sobre as filmagens é que ao falar que iria fazer um curta da praça muitos se sentiram entusiasmados em colaborar com os registros, uma forma de identificação com o seu espaço.

É nesses espaços onde se tece a trama do cotidiano: a vida do dia-a-dia, a prática da devoção, a troca de informações e pequenos serviços, os inevitáveis conflitos, a participação em atividades vicinais. É também o espaço privilegiado para a prática do lazer nos fins de semana nos bairros populares. Desta forma, o "pedaço" é ao mesmo tempo resultado de práticas coletivas (entre as quais as de lazer) e condição para seu exercício e fruição (MAGNANI, 1996, p. 13).

Nesse sentido, o que podemos dizer que a Praça 13 de Maio se constitui em um ponto de resistência cultural dentro da cidade de Mamanguape, com base nas conversas políticas e culturais que se constroem nela. Os frequentadores, em sua maioria, têm alguma relação com ações políticas e culturais na pequena e pacata Mamanguape. Muitas vezes nos encontramos para tomar uma, fumar um, tocar violão, para jogar conversa fora, para sessões livres de cinema, para um rolê de skate, $b m x^{16}$ e até mesmo para nos deslocarmos para outros locais, a praça além de um lugar para sociabilidade, apresenta-se como ponto de encontro e partida para outros locais.

Um detalhe interessante é que muitos que a frequentam também vão ao novo cinema situado no Centro Cultural Fênix, gerenciado pelo filho do antigo dono do Cine Eldorado, conhecido como Júnior da locadora ${ }^{17}$. 
O lazer apresenta-se como um elemento central da cultura vivida por milhões de trabalhadores, possui relações sutis e profundas com todos os problemas oriundos do trabalho, da família e da política que, sob sua influência, passam a ser tratados em novos termos (OLIVEN apud DUMAZEDIER, 1973, p. 19-20).

Assistem aos filmes e retornam à praça para encontrar os amigos e trocar uma ideia ou até mesmo só para estar no local. Sendo assim, a praça é um espaço de refúgio e de um lazer que é marginalizado por outros cidadãos da cidade.

\section{Notas cinematográficas}

Muito se pensou no início das filmagens, para que tudo fosse feito de maneira mais espontânea possível. No entanto, as primeiras tentativas de diálogos com a câmera nos fizeram perceber que o instrumento constrangia, incomodava não só aqueles que estavam em foco, mas também, quem estava atrás da câmera. Nas primeiras tentativas foi mais fácil conduzir as filmagens às arquiteturas da praça, seus pontos frequentados, imagens em grandes planos para pegar a praça em um plano geral e as movimentações das pessoas que se encontravam no local. Depois de alguns dias de constantes visitas a praça me foi possível fazer novas observações e interpretações sobre as dinâmicas ocorridas e, então, ter uma base de locações e horários para fazer as filmagens.

Como estamos tratando de uma praça marginalizada por parte da sociedade mamanguapense, tivemos que manobrar situações ou permitir maior conforto possível àqueles que a frequentam, para que não se sentissem abusados quanto ao uso de suas imagens e de suas seguranças individuais, pois desconheciam o objetivo do registro. Sendo assim, em todos os momentos de filmagens houve a confirmação de que aquelas imagens são conteúdos que só serão disponibilizados com a autorização dos que estiverem nela. Foi explicado qual a real intenção da câmera, no caso, o desenvolvimento de um pequeno curta sobre a Praça 13 de Maio e suas dinâmicas sociais, em especial aquelas geradoras de lazer e sociabilidade.

Do ponto de vista da experiência, o importante não é nem a posição (nossa maneira de pormos), nem a 'o-posição' (nossa maneira de opormos), nem a 'im -posição' (nossa maneira de impormos), nem a 'pro-posição' (nossa maneira de propormos), mas a 'ex-posição', nossa maneira de 'ex-pormos', com tudo o que isso tem de vulnerabilidade e de risco. Por isso é incapaz de experiência aquele que se põe, ou se opõe, ou se impõe, ou se propõe, mas não se 'expõe'. É incapaz de experiência aquele a quem nada lhe passa, a quem nada lhe acontece, a quem 
nada lhe sucede, a quem nada o toca, nada lhe chega, nada o afeta, a quem nada o ameaça, a quem nada ocorre (FERRAZ, 2014, p. 38, apud BONDÍA, 2002, p. 25).

Dito isto, comecei a produzir algumas imagens com os interlocutores desta praça e um dos métodos utilizados foi a disponibilização da câmera em suas as mãos para que eles pudessem fazer as próprias imagens. Isto permitiu uma maior relação de confiança e um diálogo que provoca uma criação cinematográfica coletiva, isto é, dialógica, sem que ela seja direcionada pelo próprio cineasta, mas sim por todos aqueles que participam e tendem a participar desta produção.

\begin{abstract}
No processo de elaboração filmica, na mis em scéne própria à pesquisa, os protagonistas da situação se interrogam e trocam suas posições. Assim, a natureza mesma do questionamento antropológico se encontra posta em questão: suas finalidades, a operação de suas escolhas de intervenção, como suas próprias dificuldades a se dizer, a exprimir a si mesma tanto fora como em seu próprio círculo (PIAULT, 1999, p. 19).
\end{abstract}

Nesse sentido, se produziu de forma compartilhada um acervo imagético da Praça 13 de Maio, para que então pudéssemos ver e analisar e editá-lo, o dotando de sentido. "A prática etnográfica associada ao cinema propiciaria o estabelecimento de uma antropologia compartilhada, alvo importante do trabalho desenvolvido por Jean Rouch" (BARBOSA e CUNHA, 2006, p. 36). A câmera utilizada foi uma CANON T3, foram feitas uma série de imagens que pudessem apresentar aos espectadores os modos de sociabilidade que a praça promove desde os tempos antigos quando o Cine Eldorado era ativo até aos dias atuais. Para tal, utilizei as fotografias antigas dos tempos do cinema para serem intercaladas ao relato oral de Walfredo David Júnior. Junto às novas imagens produzidas, evidenciei com a edição final as diferenças contextuais da praça. Foram feitas filmagens aleatórias, sempre que estive na praça e com a câmera em mãos fazia alguns planos dela, tentando captar sua estrutura, arquitetura e todos os movimentos possíveis de pessoas interagindo.

As fotografias antigas foram um instrumento essencial para possibilitar a ideia de criar novos ângulos e enquadramentos, a partir delas é que pude pensar em planos e enquadramentos que levassem o espectador a compreender a localização da praça e suas transformações no decorrer do tempo, permitindo enxergar melhor o filme e a praça. O filme se chama Praça 13 de maio: do laz̧er a resistência, o nome é um reflexo das dinâmicas de resistências e de lazer percebidas na praça. 
Mostrar não é significativo, a não ser pela organização dos dados que fazem sentido e que, então, se fazem compreender. A operação de desvelamento, realizada através da montagem das seqüências filmadas, não é nada a não ser na medida em que se faz entender, na medida que esta permite identificar seus procedimentos. Para não vir a ser uma simples mistificado, o ato de pôr em relação organizada o trabalho técnico sobre a imagem deve ser claro para o espectador. As imagens são uma realidade que não é aprendida do documento bruto (PIAULT, 1999, p. 22).

O Curta foi selecionado no Setcurtas Festival Universitário de Cinema, na Universidade Presbiteriana da Mackenzie do Rio de Janeiro-RJ, sendo exibido nos dias 06 e 07 de Setembro de 2016, causando bastante entusiasmo entre aqueles que participaram da obra. Antes já tinha feito uma exibição pública do filme na praça, mas só após as exibições no festival o disponibilizei nas redes sociais para poder dar oportunidade àqueles que ainda não haviam visto, como G, que no momento da finalização e da exibição se localizava na cidade de Campina Grande-PB, quando retornou a cidade e nos encontramos na praça, me relatou que assistiu ao filme umas seis vezes e que tinha achado "muito massa".

\section{Conclusão}

Portanto, diante dos relatos e experiências percebe-se que a Praça 13 de Maio teve ao longo do tempo níveis de sociabilidade e lazer distintos que vieram se modificando perante as novas interações e transformações sociais e econômicas da cidade. Saliento que esses diferentes níveis fazem da praça um local de lazer e convívio social dos mamanguapenses. Apesar haver repressão da Polícia Militar até os dias atuais, os frequentadores continuam a obter seu lazer e participar das sociabilidades promovidas por ela, forma de resistência à padronização da cidade imposta por valores conservadores que a todo o momento tentam excluir certos grupos das atividades da cidade.

Com isto, a Praça 13 de Maio é um berço de criações artísticas e culturais, pois élá que alguns moradores desta cidade se reúnem para conversar e construir coisas que beneficiam a sociedade mamanguapense, prova disto, o Cine Teatro Eldorado, construído e administrado pelos irmãos David ${ }^{18}$; as intervenções urbanas, as sessões de cinema livre, as festas promovidas pelo Bar Mundo da Lua e o curta Praça 13 de maio: do lazerer a resistência, o qual foi construído de forma co- 
letiva e colaboracionista, em que todos envolvidos puderam participar da produção seja direta ou indiretamente. Sendo assim, desde os tempos de "ouro" do Eldorado a praça vem possibilitando a interação entre seres humanos, permitindo a produção e a troca de conhecimento entre os indivíduos desta cidade.

\section{Notas}

1. Após a finalização do projeto e a pesquisa, defendo no dia 26 de Junho de 2016 na UFPB, Campus IV/Rio Tinto-PB o TCC intitulado Cinema no Vale do Mamanguape-PB: aproximações antropológicas, orientado pelo Prof. João Martinho Braga de Mendonça.

2. Este cachorro-quente ficou muito conhecido na cidade e no vale do Mamanguape-PB, por se localizar na praça em frente ao antigo cinema, para muitos antigos moradores era o melhor cachorro-quente da região.

3. Walfredo David Júnior é conhecido na cidade por Júnior da locadora, quando o cinema fechou ele comprou um VHS e abriu uma Locadora de filmes na cidade, segundo Júnior, muitos dos que iam ao cinema começaram a freqüentar a locadora de filmes e foi daí que ficou conhecido como Júnior da locadora.

4. No TCC intitulado Cinema no Vale do Mamanguape: aproximações antropológicas, defendido no ano de 2016, ficou claro, a partir das entrevistas e da pesquisa de campo, que independente do nível social das pessoas, elas já teriam freqüentado o cinema, desde o boteco mais barato ao canto mais refinado da cidade, nas conversas que tinha no cotidiano ao frequentar esses lugares durante o tempo de pesquisa, sempre tinha alguém que já tinha ido ao Cine Eldorado, consequentemente, participaram das atividades da Praça 13 de Maio, pois o cinema localizava-se em frente a praça.

5. Têm-se o ano de 2013 no segundo semestre o início da pesquisa, com observações e anotações no caderno de campo. A finalização das entrevistas com os interlocutores foram até o segundo semestre de 2015, quando finalizei as filmagens e a edição do filme. No entanto, algumas outras informações e observações foram buscadas no ano de 2016, momento quando a Escola de Enfermagem Rosa Mística vai se localizar em frente a praça, que algum tempo depois, abre outro bar que dinamiza ainda mais a praça. Não obstante, nos momentos de revisão deste artigo foi necessário analisar novamente algumas notas do caderno de campo e realizar outras observações na praça. Neste sentido, saliento que este artigo explana a realidade de uma praça que está em constante mudança, quando as maiores observações e análises do cotidiano da praça voltam-se entre os anos de 2013 a 2015.

6. Será abordado com mais detalhe na seção Notas cinematográficas.

7. O contato e o convívio com as pessoas da Praça sempre foi presente no meu cotidiano, outros amigos de infância já haviam me relatado sobre a classificação da praça.

8. Gala, segundo os interlocutores, é referência ao espermatozóide, líquido liberado pela ejaculação masculina. Esta nomeação da praça, surge diante do cenário que se construiu durante o tempo que a feira ficou próxima, tornando o local escuro, e a grande presença de pessoas que iam para praça durante a noite fazer sexo explícito.

9. A presença da polícia é frequente no cotidiano da Praça, especialmente a noite, período onde há maior consumo da maconha.

10. Evento que acontece todas as quintas-feiras na cidade de Rio Tinto-PB, cidade que fica a 7 


\section{José Muniz Falcão Neto}

$\mathrm{km}$ de Mamanguape-PB.

11. Sigla de abreviação do nome Rio Tinto, muitos usuários do facebook nos seus comentários e seus discursos fazem referência a palavra e a cidade de Rio Tinto-PB, pela abreviação Rt.

12. Todos os interlocutores citados deram-me permissão para o uso de seus nomes no escrito. Esta permissão foi conquistada na relação de confiança construída durante as filmagens. Quando finalizei as filmagens e os escritos falei sobre o que vinha escrevendo para aqueles que citei perguntando se poderia colocar seus nomes. No entanto, preferi ocultar algumas identidades por questões éticas e de segurança. Alguns nomes estão citados por se tratar de discursos e contextos que não se envolvem com o processo de criminalização.

13. Durante a pesquisa etnográfica, foi feito uma série de filmagens para a produção do curta metragem Praça 13 de Maio: do lazer a resistência, foi finalizado no ano de 2015, sendo feito uma exibição pública na praça para a apresentação do filme aos personagens e as pessoas que a freqüentam, o filme também está disponibilizado no Youtube.

14. Foi observado que algumas vezes alguns policiais militares se encontravam em um dos bares da praça, a interpretação que muitos dos freqüentadores tiveram é que ali era uma forma de vigilância projetada pela Polícia para possivelmente observar os seus freqüentadores e o cotidiano da praça.

15. Freqüentador da Praça 13 de Maio.

16. Modalidade esportiva feita com uso de uma bicicleta, também bastante conhecida por bicicross. São bicicletas adaptadas para fazer manobras e corridas na areia.

17. Atualmente com a transição da gestão administrativa municipal, Júnior não é mais o diretor do Centro e gerenciador do cine, o qual se encontra sobre a direção de outrem.

18. Abel David e Walfredo David.

\section{Referências}

ANDRADE, Ana I. de S. L.; VASCONCELOS, Severina M. O. de. Mamanguape 150 anos: uma cidade histórica. João Pessoa: UNIGRAF, 2005.

AURÉLIO, Jerferson. Quinta universitária. [Online], 2013. Disponível em: https://www.facebook.com/jeffersonaurelio1988/posts/1437204843158767 Acesso: 27/11/2013.

BARBOSA, Andrea; CUNHA, Edgar T. Antropologia e Imagem. Rio de Janeiro: Jorge Zahar, 2006.

COSTA, Flávia C. O primeiro cinema: espetáculo, narração, domesticação. Rio de Janeiro: Azougue Editorial, 2005.

DUMAZEDIER, Joffre. Lazer e cultura popular. Tradução de Maria de Lourdes Santos Machado. São Paulo: Perspectiva, 1973.

ELIAS, Norbert; SCOTSON, John L. Os estabelecidos e os outsiders: sociologia 
das relações de poder a partir de uma pequena comunidade. Tradução de Vera Ribeiro. Rio de Janeiro: Jorge Zahar, 2000.

FERRAZ, Ana L. Etnografia em filme e ensino de antropologia: apontamentos de sala de aula. In: FERRAZ, Ana L.; MENDONÇA, João M. B. de (Orgs.). Antropologia Visual: Perspectivas de ensino e pesquisa. Brasilia: ABA, 2014.

GUBER, R. El trabajo de campo como instancia reflexiva del conocimiento. In: El Salvage metropolitano. Buenos Aires: Paidós, 2005.

MAGNANI, José G. C. Quando o campo é a cidade: fazendo antropologia na metrópole. In: MAGNANI, José G. C.; LUCCA, Lilli (Orgs.). Antropologia Urbana e os desafios na Metrópole. São Paulo: EDUSP, 1996.

OLIVEN, Ruben George. A Antropologia de Grupos Urbanos. 6. ed. Petrópolis, RJ : Vozes, 2007.

PIAULT, Marc Henri. Espaço de uma antropologia audiovisual. In: ECKERT, Cornelia; MONT-MÓR, Patricia. Imagens em foco: novas perspectivas em antropologia. Porto Alegre: Ed. Universidade/UFRGS, 1999, pp. 13-30.

QUEIROZ, Maria I. P. de. Relatos Orais: do “indizível” ao “dizível”. São Paulo: Vértice, 1988.

SILVA, Sóricri F. da. Cine Teatro Eldourado: modernidade e cotidiano na Mamanguape (PB) do séc. XX. 2012. Trabalho de Conclusão de Curso (Graduação em História), Universidade Estadual da Paraíba, Guarabira, 2012.

VELHO, Gilberto. Desvio e divergência: uma crítica da patologia social. 8. ed. Rio de janeiro: Jorge Zahar, 2003. 


\title{
Praça 13 de Maio: from the Eldorado cinema to the present day
}

\begin{abstract}
This article tries to show practices of sociability and leisure built in a certain period of time in 13 de Maio Square, located in the city of Mamanguape/PB. Starting from direct observations of old photographs, oral reports and filming, it was perceived how these practices present importance within the social level of the city. For that, the in-loco vivance was fundamental to have an understanding of the constitutive processes of the square. Thus, the objective here presented is to show some ethnographic experiences taken during the time of vivance in the square, analyzing the groups, individuals, the forms of sociability generated in times of the cinema (Cine Teatro Eldorado) and the new corners and leisure forms that present themselves as acts of resistance.
\end{abstract} Keywords: Urban Anthropology; Cinema; Sociability; Leisure; Resistance.

Recebido em 19 de abril de 2017. Aceito em 28 de julho de 2017. 